\title{
Nyema Droma in Conversation
}

\author{
Yuyuan (Victoria) Liu, Columbia University
}

Nyema Droma is a photographer and curator born and based in Lhasa. Nyema received her $B A$ in Fashion Photography and Styling from the London College of Fashion. She is best known for Performing Tibetan Identities, a portrait series of 'new' generation of global Tibetans, which was exhibited at the Pitt Rivers Museum in 2018. Nyema's artwork features on cover of the inaugural issue of Waxing Moon and here she shares her most recent projects, future plans and her reflections on her multiple roles in the world of Tibetan visual culture.

You started fashion photography in university and your early work largely consisted of fashion shoots of Tibetan subjects. How did your early experiences influence your current approach to photography? What inspired your transition to becoming a contemporary photographer?

My early experiences in fashion photography in London have had a great influence on my current work. Working in the fashion industry definitely inspired me in different ways to establish my own brand Hima Alaya. Being exposed to different people from diverse backgrounds in the industry has also taught me how to cooperate with my team members today. As a contemporary Tibetan photographer, I create works that explore issues like cultural identities, selfrepresentation, globalization and social status that play out in contemporary Lhasa. I enjoy being able to present different ideas and concepts through photographs while adding fashion elements and artistic aesthetics to the photographs. Photography has served as a bridge for me to learn more about people and their stories and histories. My camera is a medium through which I express my feelings, thoughts and questions to the audience.

\section{Could you tell us a bit about your exhibition Performing} Tibetan Identities at the Pitt Rivers Museum in 2018 and your personal experience of interviewing your subjects for the exhibition?

The exhibition "Performing Tibetan Identities" was a photo series project that includes 30 young Tibetans from diverse backgrounds, class, profession and political status. In 2015 at an exhibition in London, I met Clare Harris who was then the curator at the museum. After many meetings with her at Oxford, I was offered an artist residency at the Pitt Rivers Museum, and we came up with the 
"Performing Tibetan Identities." As a Tibetan who grew up in a very diverse culture, I often have many questions about my own identity, and sometimes have trouble balancing my cultural identity and modern identity in contemporary society. On many occasions I feel that I am only performing my Tibetan identity, such as when I put on traditional dress in front of the camera. Like I said earlier, my camera is a medium through which I ask questions and learn about stories. This is why I want to interview different people and investigate their answers towards my questions.

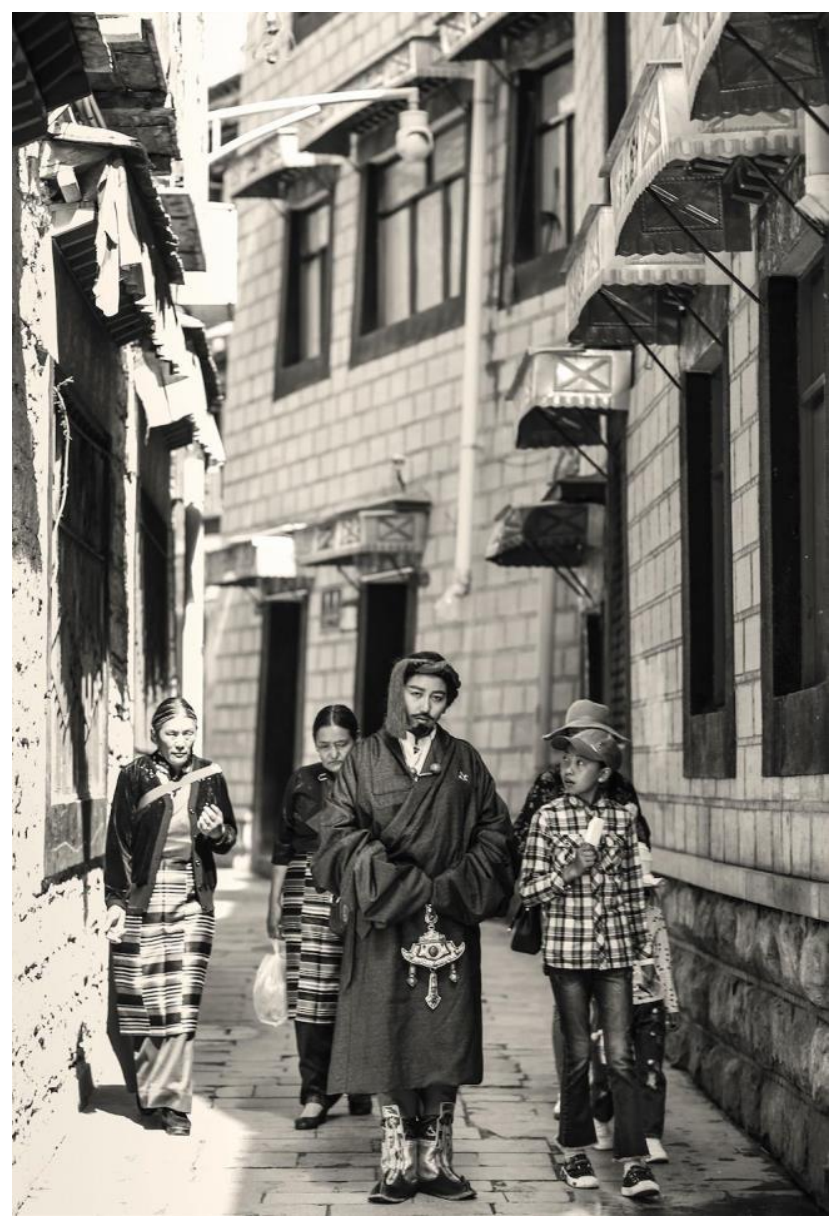

Nyema Droma's Self-Portrait from Performing Tibetan Identities project

\section{Could you tell us about your recent clothing collection for monks and nuns?}

Our new collection 'Lhaksum' (lhag bsam) is a monastic clothing series specially designed for the lifestyles of the modern sangha from the perspective of fabric and function, and made from the sincere wish to repay their purity of their faith. This series was something I have been wanting to work on since 2016 while I was studying and teaching in 
Dromaling Monastery in Yushu. After spending most of my time with monks and nuns that year and getting to know their living environments and daily lifestyle, I wanted to make something that's suitable and functional for them.

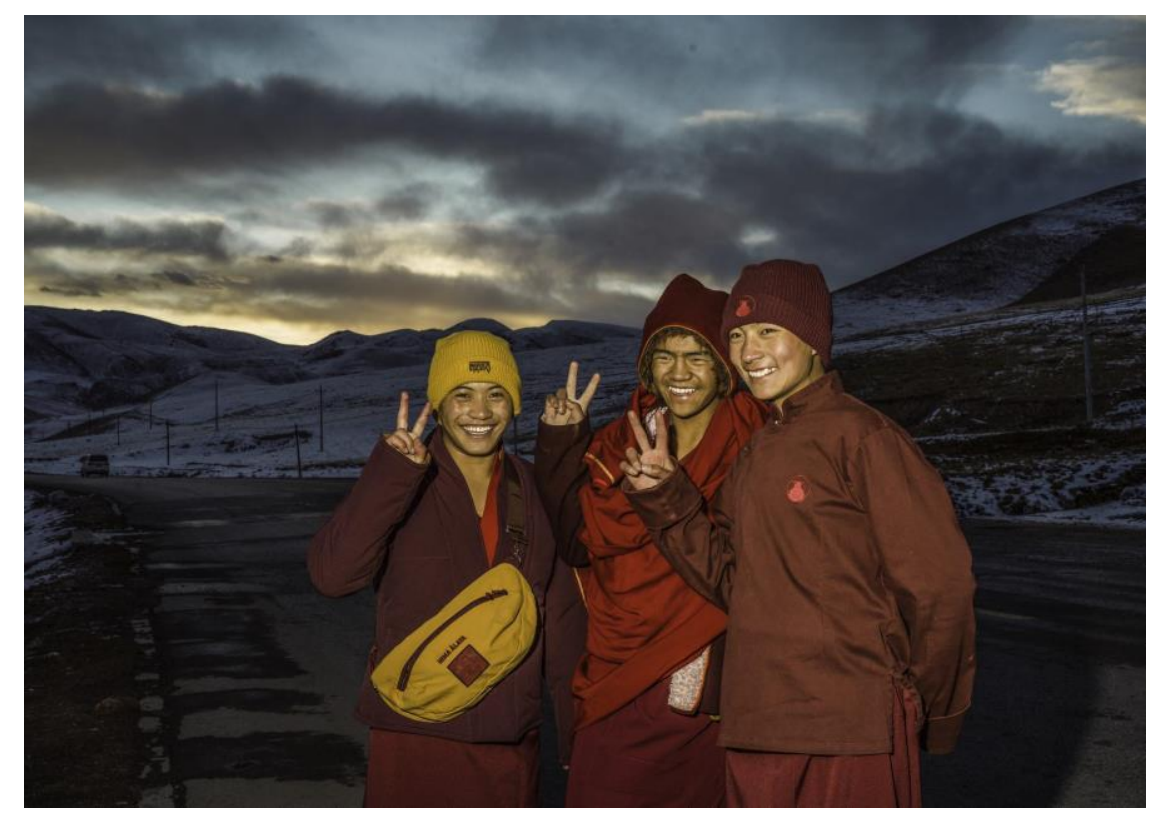

You also curate exhibitions, host art festivals and photography competitions. How do you negotiate your multiple roles as a photographer, designer, curator and business owner?

From my experiences as an artist, I had many opportunities to get to know many other interesting roles in the art industry. I love to explore new things and challenges and it is fascinating to see how people react and feel when they come to exhibitions or events we host in Lhasa. I have always aspired to do things that are meaningful and inspiring for my community, promoting an artistic atmosphere in Lhasa and portraying a modern Tibetan image to a wider and more international audience.

\section{What's next?}

I plan to finish my master's degree and expand my brand to an international market. At the same time, I hope to curate events and exhibitions in Lhasa that are centered on social values. For my MA research, I want to work on helping local Tibetan artists connect with global communities so that they can reach broader audiences and their work can be subject to more diverse interpretations. I also want to collaborate with artists from other backgrounds to create more Tibetan and Himalayan culture-based artworks. I think these works could stimulate new conversations among Tibetan artists and their audiences 
as they see ideas, expressions, visions and interpretations surrounding Himalayan culture from the west.

You have designed the cover of our first issue. What were your creative ideas?

This cover was shot in 2018 during my visit to Tashi Choede monastery in Gonkar county, Lhoka (also known as Gongkar Chö Monastery). Although many wall paintings at the monastery were destroyed during the Cultural Revolution, the site has some of its original traces preserved. It is always fascinating for me to see traditional artworks in monasteries and to appreciate them in my own way.

\section{Which artists and photographers inspire you the most?}

I really admire the early generation of Tibetan contemporary artists, such as Gonkar Gyatso, Nortse and Gade. I think these artists create works that truly reflect their communities and comment on their social reality. They are artists who are very expressive and socially aware. 